\title{
Greenland's Island Rule and the Arctic Ocean circulation
}

\author{
by Terrence M. Joyce ${ }^{1,2}$ and Andrey Proshutinsky ${ }^{1}$
}

\begin{abstract}
In order to explain observed southward water transport of 2-3 Sv through Davis Strait, a simple extension of Godfrey's (1989) Island Rule and a 2-D idealized numerical model simulations were made for the flow around Greenland. Godfrey's theory has been extended to permit inclusion of Bering Strait inflow and bottom friction to represent the dissipation supplied by the porous Canadian Archipelago in the modeled flow west of Greenland. In both models, the forcing has been applied in a quasi-steady manner to the circulation via climatologic wind stresses and using wind forcing for the high and low Arctic Oscillation (AO) index states. It is found that climatologic wind produces an overall cyclonic flow around Greenland. This flow is increased under winds of a positive AO index and reduced, even becoming anti-cyclonic during a negative AO phase. Model experiments show that increase of model friction results in the blocking of flow west of Greenland (decrease of water transport in Davis Strait) and a shift of more flow to the east of Greenland. Model tuning to agree with direct measurements of transport in the Davis Strait is sensitive to both the forcing and the dissipation. Numerical experiments are also run to illustrate the dependence of the physics on bathymetric variations from a flat 200-m deep ocean, on lateral friction, and on properly resolving the flow in the archipelago with the numerical model. The circum-Greenland transport by winds can exceed the Bering Strait inflow and account for most of the observed flow (ca. -2.5 Sv) to the west of Greenland. Poor representation of Canada Strait opening in the numerical models can result in the intensification of the East Greenland Current and in the reduction of the Atlantic water inflow to the Arctic Ocean.
\end{abstract}

\section{Introduction}

Here we apply Godfrey's (1989) Island Rule to Greenland. The theoretical framework of Pedlosky et al. (1997) will be followed, for a barotropic, flat-bottomed fluid. But Godfrey's idea, originally suggested for a stratified, wind-driven 'layer', which does not feel the bathymetry, is closer to the ocean model we envision: one that tries to explore the wind-driven dynamics of the Arctic flow in the upper fresh layers influenced by the Pacific inflow which sits atop the deeper, salty Atlantic layer, and a freshwater cap, formed by melting sea ice and river runoff, which sits atop the Pacific layer. In terms of what water can readily re-circulate around Greenland, these are the only two layers to consider, since

1. Department of Physical Oceanography, Woods Hole Oceanographic Institution, Woods Hole, Massachusetts, 02543, U.S.A.

2. Corresponding author.email: tjoyce@whoi.edu 


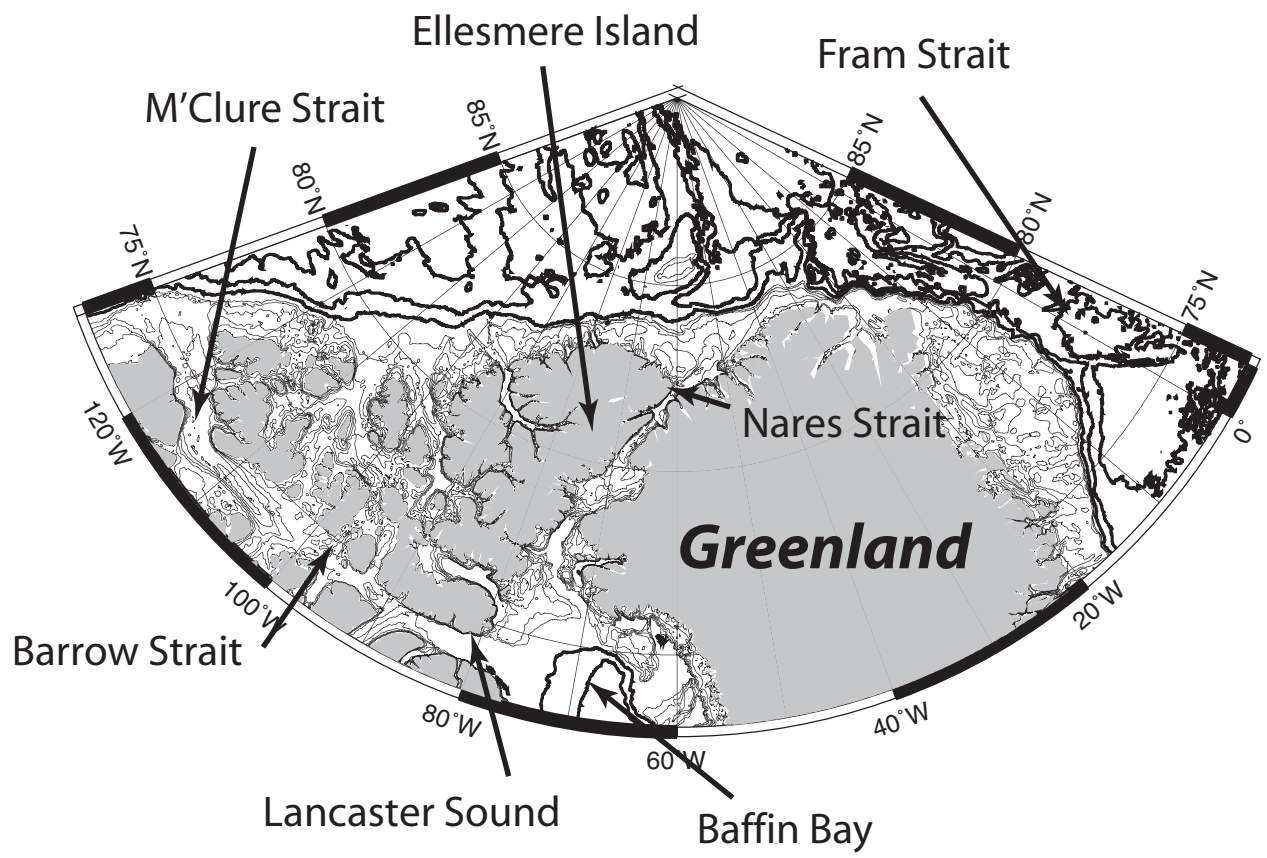

Figure 1. Ocean bathymetry around Greenland is given with $100-\mathrm{m}$ depth contours to $500 \mathrm{~m}$ (light lines) and 1000-m increments (heavy lines) thereafter.

passages to the west of Greenland block the flow of waters deeper than ca. 200-m depth. A major point of issue is the connectedness of the western sea boundary of Greenland between the Arctic and the Subarctic Atlantic (Fig. 1). The Canadian Archipelago, Nares Strait, Baffin Bay, and the Labrador Sea all form this western side to the 'island' of Greenland. Of these, Nares Strait between Ellesmere Island and Greenland is the narrowest (ca. 40-50 km), yet most direct route for flow to the west of Greenland. Recent measurements indicate there is a net mean flow out of the Arctic through this narrow passage (Münchow et al., 2006). The second direct route is through M'Clure and Barrow straits, and Lancaster Sound, between Devon and Baffin islands, approximately along the latitude of $74 \mathrm{~N}$. These and other narrow and sometimes shallow passages create a porous boundary through which approximately 2-3 Sv of water flows to the south, as observed by Cuny et al. (2005) and Lee et al. (pers. comm., 2006) in Davis Strait to the west of Greenland. Additional flow to the southeast from Hudson Strait (Straneo, pers.comm., 2006) supplements this porous flow to the west of Greenland. This volume transport exceeds that flowing into the Arctic from Bering Strait (Woodgate et al., 2006) by a factor of three and one purpose for this study is to try to explain this. One consequence of the porosity of the ocean to the west of Greenland is that friction will be a necessary, though complicating, process that needs attention, similar to the porous flow through the Indonsesian Passages discussed by Wajsowicz (1996). 


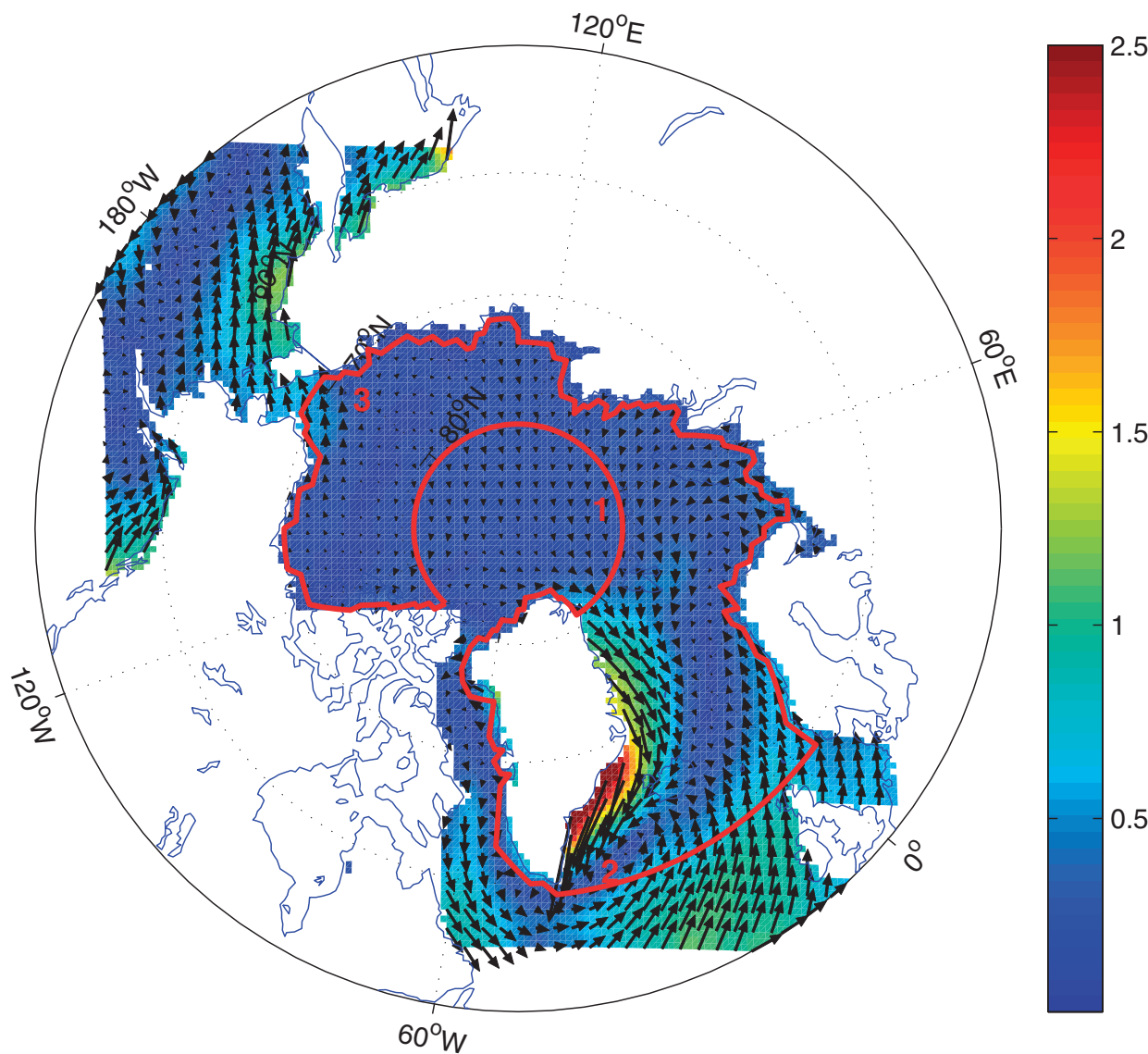

Figure 2. Mean wind stress amplitude (colors) in cgs units, vectors (arrows), and integration path $P$ (red line), for the Island Rule calculation. The numbers in red refer to three different zonal regions where meridional transports are important. Several large islands (e.g. Iceland, Spitzbergen) have been removed for clarity.

\section{Island Rule dynamics}

The Island Rule method will now be presented. The integration path to be used, along with the mean annual wind stress, is presented in Figure 2. Certain coastal irregularities and small islands (compared to Greenland) have been removed for simplicity. In addition, the geometry of the Canadian archipelago has been simplified by making the single passage to the Arctic an expanded Nares Strait and making all of the rest of the islands and passages one solid land mass attached to Canada. This is not done later in the numerical model calculation.

Following Pedlosky et al. (1997), for a barotropic fluid of constant density $\rho$ and depth $H$, driven by a surface stress, $\vec{T}$ :

$$
\vec{u}_{t}+(\zeta+f) \vec{k} \times \vec{u}=-\nabla(p / \rho+\vec{u} \cdot \vec{u} / 2)+\operatorname{Diss}(\vec{u})+\vec{T} / \rho H,
$$


where $f$ and $\zeta$ represent the planetary and local vorticity, and the viscous dissipation of momentum, $\vec{u}$, is given by $\operatorname{Diss}(\vec{u})$. If one integrates this equation around a closed path $P$, which is defined in Figure 2, and uses the fact that the normal flow at solid boundaries vanishes, one obtains the following:

$$
\begin{gathered}
\partial_{t} \oint_{P} \vec{u} \cdot \overrightarrow{d l}+\oint_{P}(\zeta+f)(\vec{k} \times \vec{u}) \cdot \overrightarrow{d l}=\oint_{P}[\operatorname{Diss}(\vec{u})+\vec{T} / \rho H] \cdot d l \\
\text { where } \oint_{P} \nabla(p / \rho+\vec{u} \cdot \vec{u} / 2) \cdot \overrightarrow{d l}=0, \\
\quad \text { and } \oint_{P} \operatorname{Diss}(\vec{u}) \cdot \overrightarrow{d l} \approx-R L v_{c}, \\
\text { and } \oint_{P}(\zeta+f)(\vec{k} \times \vec{u}) \cdot \overrightarrow{d l} \approx-f_{1} \int_{1} d x v_{1}-f_{2} \int_{2} d x v_{2}-f_{3} \int_{3} d x v_{3}
\end{gathered}
$$

In (2), the subscripted values $1,2,3$ of $f, v$, refer to the value of the Coriolis parameter and meridional velocity, at each of the latitudes of meridional oceanic flow (Fig. 2), and $L$ is the length of the frictional channel to the west of Greenland. Because the path is closed, the pressure $(p)$ terms drop out. Since the velocity normal to the solid boundaries is zero, the only contribution from the second term in (2) is from three regions where we can have normal flow into the closed region. We linearize and simplify the dissipation by bottom friction as all appearing in the channel to the west of Greenland. The linear friction parameter, $R$, which multiplies the velocity within the channel, $v_{c}$, is an unknown quantity at present. Regardless of the direction of flow to the west of Greenland, friction acts to dissipate contributions to the circulation integral.

The three meridional transports and the dissipation in the channel to the west of Greenland can all be simplified by using a horizontal volume transport streamfunction, $H(u, v)=\left(-\Psi_{y}, \Psi_{x}\right)$. The streamfunction, $\psi$, takes on values of 0 on Eurasia, $\Psi_{g}$ on Greenland, and $\Psi_{b}$ on N. America. The latter is assumed to be known (transport thru Bering St.), while the value on Greenland is what we want to find. With these substitutions, and assuming steady flow, our line integral relation becomes:

$$
\left(f_{1}-f_{2}+R L / W\right) \psi_{g}=\left(f_{1}-f_{3}+R L / W\right) \psi_{b}-\oint_{P} \vec{T} / \rho \cdot d \vec{l},
$$

where the width of the channel is $W$. The key forcing other than the flow through the Bering Strait, is from the wind stress, evaluated as the line integral of wind around the rather convoluted integration path. Without any wind forcing, there will be a non-zero value of the streamfunction on Greenland due to the inflow from the Bering Strait. This inflow, 
which occurs at about $70 \mathrm{~N}$ into the control volume, is balanced by outflows across $60 \mathrm{~N}$ into the N. Atlantic, and across $80 \mathrm{~N}$ into the passage to the west of Greenland. Planetary vorticity constraints will cause the circulation around the path to change if there is a net vorticity flux into the control volume. If all of the Bering Strait inflow flows out to the east of Greenland, there is a net planetary vorticity flux into the Arctic, while if the outflow is to the west of Greenland, there is a net loss of planetary vorticity by the Arctic control volume. The balance in (3) represents what is required for no net planetary vorticity flux. Yang (2005) considered a similar dynamic, although his model results are more complicated because of bathymetric changes, which we ignore here.

In the limit of no friction, the streamfunction value on Greenland is ca. $60 \%$ of the Bering Strait inflow, while in the limit of large friction, the value of $\psi_{g}$ becomes the same as the inflow from Bering Strait: in other words, for large friction there is no net transport to the west of Greenland and all of the Bering Strait inflow passes to the east of Greenland. For zero friction, 59\% of the inflow flows south to the west of Greenland. We will choose a value of friction, $R$, that is small compared to the usual geostrophic terms. However, this seemingly small value can become large because of two factors. First, its dynamical effect is multiplied by the ratio of the length/width of the 'channel', which is of order 10 . Secondly, it must be compared not with the Coriolis parameter, but with the difference in Coriolis parameters at bounding latitudes. We will choose a value of $R L / W=0.2^{*} f_{1}$. In this case, $23 \%$ of the Bering Strait inflow can be expected to the west of Greenland with no wind forcing. The reason for this choice of friction will become clear soon.

We turn now to the wind-driven flow, which involves evaluation of the line integral of wind stress along the integration path in (3). Wind data used in our study represent the wind climatology derived from NCAR/NCEP reanalysis product. The wind stresses are calculated from 6-hourly sea-surface atmospheric pressure fields and averaged for 1948-2005 to represent "mean" wind. We also averaged 6-hourly wind stresses for the years which Arctic Oscillation (AO) (Thompson and Wallace, 1998) index exceeded one standard deviation of index variability for both positive and negative phases. We use the following AO positive years: 1967, 1975, 1989, 1990, and 1992. AO negative years are: 1958, 1960, 1966, 1969, 1980, and 1985.

First, the value of the streamfunction on Greenland can be obtained from (3) by division by $\left(f_{1}-f_{2}+R L / W\right.$ ). For the mean winds (Fig. 2), we show the cumulative contribution to $\psi_{g}$ due to the wind stress integral for a Bering Strait inflow of 1 Sv. (Fig. 3), starting from the initial value set by the Bering Strait throughflow. One can see the importance of the wind-driven transport over the inflow from Bering Strait. The net flow around Greenland is cyclonic, with an upper bound of about $5 \mathrm{~Sv}$, given by the frictionless limit. In large part, one can see this by looking at the wind field (Fig. 2). It is relatively strong and to the east in the direction of the integration between the southern tip of Greenland and Europe. This is where the main contribution to the forcing occurs. It is a region largely free of ice cover, and thus our calculation is not dominated by contributions from regions where direct action of the winds are shielded from the ocean by seasonal or even permanent ice cover. Elsewhere, there is cancellation of forcing, leaving this particular region as the most 


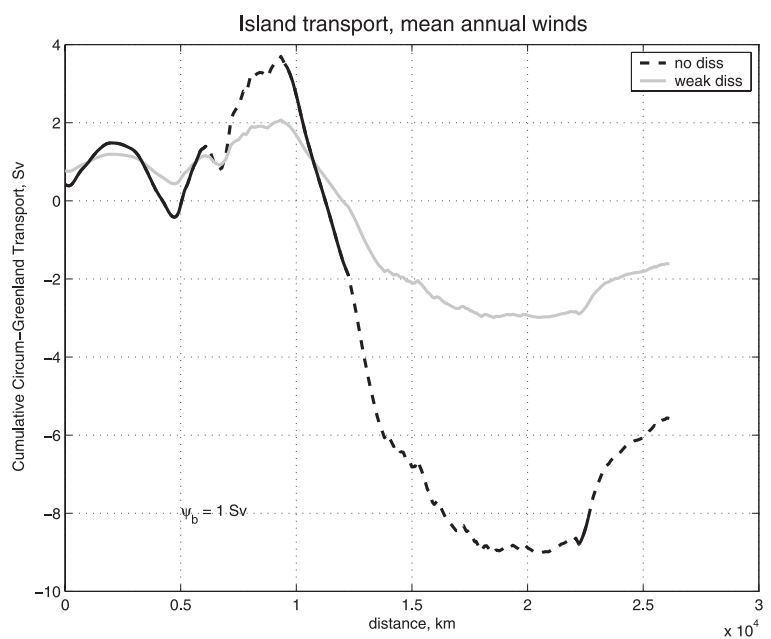

Figure 3. Island rule calculation for mean annual wind forcing with Bering Strait inflow of $1 \mathrm{~Sv}$. The frictionless value for the streamfunction on Greenland, $\psi_{g}$, is ca. $-5 \mathrm{~Sv}$, while that for weak dissipation is ca. $-1.5 \mathrm{~Sv}$. Since the net transport west of Greenland is $\psi_{b}-\psi_{g}$, this would imply a net southward transport of 6 (frictionless) or 2.5 (frictional) Sv, and a northward transport of 5 (frictionless) or 1.5 Sv. to the east of Greenland. Contributions to the line integral are plotted against distance along the path, starting at the northern tip of the land mass to the west of Greenland and integrating westward along the zonal path at $80 \mathrm{~N}$. Contributions to the integral from oceanic regions along path segments 1,2, and 3 are shown as solid lines for no dissipation, all others as dashed.

critical for circum-Greenland wind-driven flow. Our use of latitude circles for the integration path over water leaves a small portion of the path (Fig. 2) attached to the western boundary of Greenland in the far north. Without changing the results we could have lightly 'tilted' the path so as to arrive exactly at the northern tip of the island, thus avoiding this source of dissipation in our integral, which we have ignored. This is because the wind torque over this northern path 1 is weak and our result is insensitive to small changes in the path at this latitude (Fig. 3). The frictional value in the Island Rule calculation was chosen to produce an amplitude of the southward transport to the west of Greenland consistent with the observations $(-2.5 \mathrm{~Sv})$. It turns out that these observations are more typical of mean forcing conditions than anomalous forcing at either of the two extreme phases of the AO. Using the climatological wind data we see that substantial change in this circulation may be expected on decadal time scales (Table 1). In particular, the flow may reverse direction during low phases of the AO. In this table we also show selected results from a numerical model, presented next.

\section{Numerical model results}

In addition, a 2-D $13.89 \mathrm{~km}$ horizontal resolution vertically integrated coupled ice-ocean barotropic model developed by Proshutinsky (1993) was used to investigate the above 
Table 1. Comparison of Island Rule transports with and without friction and a numerical calculation for a barotropic, flat bottom model. In all cases there is an inflow into the Arctic Ocean of $1 \mathrm{~Sv}$ through Bering Strait. The different columns are for no winds, mean winds, high and low AO states. Positive transports are poleward in the table, and volume transports west and east of Greenland are shown. Model results are shown for the 'normal' friction case in Table 2.

\begin{tabular}{|c|c|c|c|c|}
\hline & $\begin{array}{l}\text { No winds } \\
\text { (1 Sv inflow) }\end{array}$ & $\begin{array}{l}\text { Mean winds } \\
\text { (1 Sv inflow) }\end{array}$ & $\begin{array}{c}\mathrm{AO}+ \\
(1 \mathrm{~Sv} \text { inflow })\end{array}$ & $\begin{array}{c}\mathrm{AO}- \\
(1 \mathrm{~Sv} \text { inflow })\end{array}$ \\
\hline Island Rule no friction & $\begin{array}{l}-0.59 \mathrm{~Sv} \text { west } \\
-0.41 \mathrm{~Sv} \text { east }\end{array}$ & $\begin{array}{l}-6.46 \mathrm{~Sv} \text { west } \\
+5.46 \mathrm{~Sv} \text { east }\end{array}$ & $\begin{array}{l}-27.7 \mathrm{~Sv} \text { west } \\
+26.7 \mathrm{~Sv} \text { east }\end{array}$ & $\begin{array}{l}+6.46 \mathrm{~Sv} \text { west } \\
-7.46 \mathrm{~Sv} \text { east }\end{array}$ \\
\hline Island Rule weak friction & $\begin{array}{l}-0.23 \mathrm{~Sv} \text { west } \\
-0.77 \mathrm{~Sv} \text { east }\end{array}$ & $\begin{array}{l}-2.57 \mathrm{~Sv} \text { west } \\
+1.57 \mathrm{~Sv} \text { east }\end{array}$ & $\begin{array}{l}-9.85 \mathrm{~Sv} \text { west } \\
+8.85 \mathrm{~Sv} \text { east }\end{array}$ & $\begin{array}{l}+2.57 \mathrm{~Sv} \text { west } \\
-3.57 \mathrm{~Sv} \text { east }\end{array}$ \\
\hline Barotropic 200-m model & $\begin{array}{l}-0.32 \mathrm{~Sv} \text { west } \\
-0.68 \mathrm{~Sv} \text { east }\end{array}$ & $\begin{array}{l}-2.66 \mathrm{~Sv} \text { west } \\
+1.66 \mathrm{~Sv} \text { east }\end{array}$ & $\begin{array}{l}-4.15 \mathrm{~Sv} \text { west } \\
+3.15 \mathrm{~Sv} \text { east }\end{array}$ & $\begin{array}{l}-1.01 \mathrm{~Sv} \text { west } \\
+0.01 \mathrm{~Sv} \text { east }\end{array}$ \\
\hline
\end{tabular}

formulated problem. This model does not have thermodynamics, sea ice thickness is fixed and corresponds to the mean climatic conditions (Proshutinsky and Johnson, 1997), and sea ice concentration is prescribed monthly from observations. The sea ice dynamics includes internal ice forces introduced by Rothrock (1975). The model was fully tested and calibrated against observed sea level time series along the Siberian coast line and sea ice drift data from the International Arctic Buoy program (IABP, http://iabp.apl.washington. edu/) in Proshutinsky (1993) and Proshutinsky and Johnson (1997). This model in slightly different formulation (without atmospheric forcing) was used to simulate Arctic tides (Kowalik and Proshutinsky, 1994). It also was used to investigate and predict storm surges in the Arctic Ocean (Proshutinsky, 1993) and it has been employed as operational at the Arctic and Antarctic Research Institute (St. Petersburg, Russia) to predict sea ice conditions and sea level variability in the Arctic Ocean (http://www.aari.nw.ru/clgmi/forecast/ fc_2.html)

Initially, the dependent variables in the integration domain are taken as zero. Along the solid boundary we assume a no-slip condition for water transport and ice velocity. To solve equations with initial and boundary conditions, a semi-implicit finite-difference scheme with central differences on Arakawa $\mathrm{C}$ grid was employed. With the $13.89 \mathrm{~km}$ horizontal resolution this model resolves straits of the Canadian Archipelago very well (5 grid points in the narrowest part of Nares Strait).

The model was forced by winds and by water inflow via Bering Strait. At the open model boundary in the North Atlantic we prescribed radiation conditions. A set of numerical experiments was carried out employing this model and their results are shown in Tables 1 and 2. Our case for a flat bottom of constant 200-m depth (Fig. 4) corresponds to the Island Rule model discussed in the previous section. We have also considered real bathymetry (full-depth ocean) and only Bering Strait inflow with and without sea ice to force the model. Our other experiments intended to investigate water fluxes for different regimes of the wind-driven circulation, namely: for the climatologic mean wind stresses, and for wind corresponding to high and low AO indexes. 
Table 2. Results of numerical experiments with the 2-D barotropic coupled ice-ocean model. For the control model run the bottom drag coefficient, $C_{d}$ is 0.0026 and the lateral friction coefficient is $10^{8} \mathrm{~cm}^{2} / \mathrm{s}$. For the case of reduced friction these coefficients are 0.0 and $4 \times 10^{7} \mathrm{~cm}^{2} / \mathrm{s}$, respectively. In all cases there is an inflow into the Arctic Ocean of $1 \mathrm{~Sv}$ through Bering Strait. The different columns are for no winds, mean winds, high and low AO state winds. Positive transports are poleward in the table, and volume transports west and east of Greenland are shown.

$\begin{array}{cccc}\text { No winds } & \text { Mean winds } & \mathrm{AO}+ & \mathrm{AO}- \\ (1 \mathrm{~Sv} \text { inflow }) & (1 \mathrm{~Sv} \text { inflow }) & (1 \mathrm{~Sv} \text { inflow }) & (1 \mathrm{~Sv} \text { inflow })\end{array}$

Real bathymetry

$-0.23 \mathrm{~Sv}$ west $+0.01 \mathrm{~Sv}$ west

$-0.11 \mathrm{~Sv}$ west

$+0.07 \mathrm{~Sv}$ west

$-0.77 \mathrm{~Sv}$ east

$-1.01 \mathrm{~Sv}$ east

-0.89 Sv east

$-1.07 \mathrm{~Sv}$ east

Real bathymetry and

$-0.27 \mathrm{~Sv}$ west

$+0.08 \mathrm{~Sv}$ west

$-0.12 \mathrm{~Sv}$ west

$+0.25 \mathrm{~Sv}$ west

reduced friction

$-0.73 \mathrm{~Sv}$ east

$-1.08 \mathrm{~Sv}$ east

$-0.88 \mathrm{~Sv}$ east

$-1.25 \mathrm{~Sv}$ east

Flat 200-m bottom except

depth $<200 \mathrm{~m}$

$-0.10 \mathrm{~Sv}$ west

$-1.05 \mathrm{~Sv}$ west

$-1.12 \mathrm{~Sv}$ west

$-0.40 \mathrm{~Sv}$ west

$-0.90 \mathrm{~Sv}$ east

$+0.05 \mathrm{~Sv}$ east

$+0.12 \mathrm{~Sv}$ east

$-0.60 \mathrm{~Sv}$ east

Barotropic 200-m model

$-0.32 \mathrm{~Sv}$ west

$-2.66 \mathrm{~Sv}$ west

$-4.15 \mathrm{~Sv}$ west

$-1.01 \mathrm{~Sv}$ west

$-0.68 \mathrm{~Sv}$ east

$+1.66 \mathrm{~Sv}$ east

$+3.15 \mathrm{~Sv}$ east

$+0.01 \mathrm{~Sv}$ east

Flat 200-m bottom and reduced friction

$-0.35 \mathrm{~Sv}$ west

$-0.65 \mathrm{~Sv}$ east

$-4.29 \mathrm{~Sv}$ west

$-6.54 \mathrm{~Sv}$ west

$-1.61 \mathrm{~Sv}$ west

$+3.29 \mathrm{~Sv}$ east

$+5.54 \mathrm{~Sv}$ east

$+0.61 \mathrm{~Sv}$ east

The experiments with real bathymetry (see experiments with real bathymetry in Table 2) showed that the bathymetry constraint (flow follows $f / H$ contour and propagates along Alaskan, Canada and Greenland continental slopes toward Fram Strait) plays a significant role in the redistribution of this flow between west and east of Greenland, and the outflow via Fram Strait always dominates water flux via Canada Straits without winds. Winds change this ratio depending on wind strength and prevailing direction. Model friction plays a role and manipulations with bottom and lateral friction in the ocean and sea ice models allow us to tune them and make results comparable with observations.

In the next experiments (flat 200-m bottom except depths less than $200 \mathrm{~m}$ ) we assumed that wind action is concentrated in the upper $200 \mathrm{~m}$ of the ocean because the Arctic Ocean is strongly stratified as discussed above, but bathymetric changes shallower than $200 \mathrm{~m}$ were retained. Interestingly, for the case of Bering inflow without wind forcing, more water goes to Canadian Straits (up to 32\%) when the bottom is flat then for either of the cases for variable topography. This can be seen by comparing Figure 4 (left) and Figure 5, where water circulation patterns are shown for these experiments.

In Figure 5 (left, real bathymetry), the water flow turns right after leaving Chukchi Sea shelf and follows to Fram Strait along continental slope. When it passes Canada Straits some water goes to Baffin Bay via straits (from $10 \%$ to $35 \%$ depending on friction). In the case of a flat bottom for depths below $200 \mathrm{~m}$ (Fig. 5, right) the major stream leaving Chukchi Sea shelf turns right because the Chukchi and Beaufort seas have depths less than $200 \mathrm{~m}$ and the stream "feels" this slope. Later, in the eastern Beaufort Sea this flow turns left because the shelf is very narrow in this region and the flow deflects left resembling the circulation pattern in Figure 5 (left) where the ocean bottom is flat with a constant 200-m 


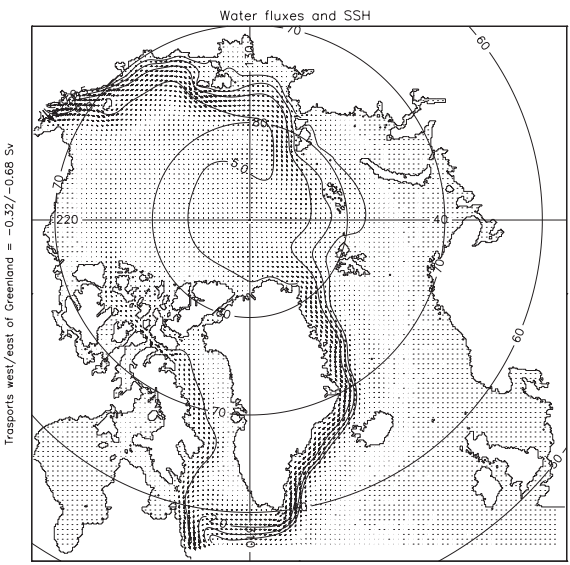

Flat bottom $=200 \mathrm{~m}$. Bering Strait inflow $15 \mathrm{v}$. Nox flux vector $=10 \mathrm{~mm} / \mathrm{s}$

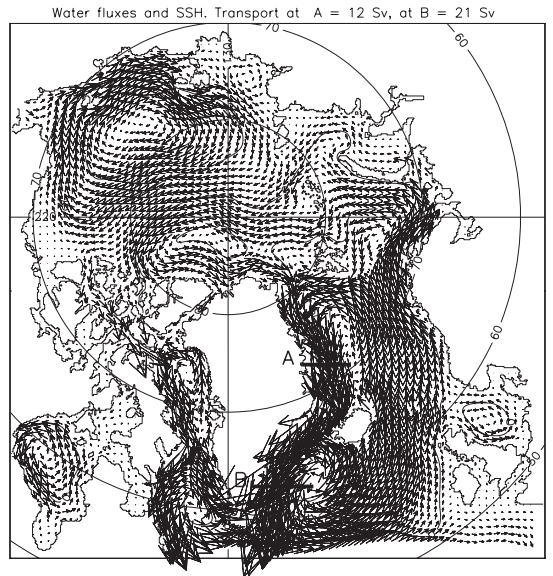

Flat bottom $=200 \mathrm{~m}$. Bering Strait inflow $15 \mathrm{v}$. Nax flux vector $=72 \mathrm{~m} \times 2 / \mathrm{s}$

Figure 4. A steady, flat bottom, 200-m deep barotropic ocean model calculation has been run which is forced by a Bering Strait inflow of $1 \mathrm{~Sv}$ only (left) and the same inflow with the mean wind stress (right). Without wind, the major export route for fluid from the Arctic is to the east of Greenland. Wind forcing shifts this to the west of Greenland with net inflow into the Arctic to the east of Greenland. Vectors and sea-surface height (contours, $\mathrm{cm}$ ) have been scaled differently in each panel. These calculations were done with reduced lateral friction (Table 1). The volume transport of the East Greenland Current (EGC, right panel) has been calculated across two lines: A and B.

depth everywhere. The turn in Figure 5 (right) results in the significant decrease of outflow via Canada Straits. In the case of constant depth, the transport west of Greenland is increased because of the more uniform redistribution of flow in the entire region. In the

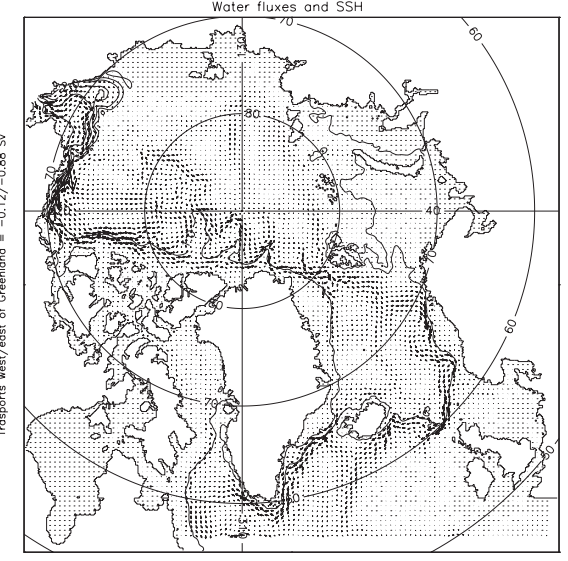

Reol bothymetry. Bering Stroit inflow 1 Sv. Mox flux vector $=26 \mathrm{~m} \times 2 / \mathrm{s}$

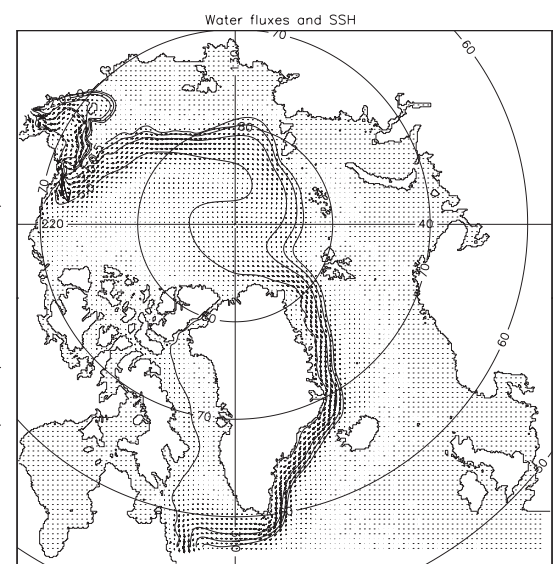

No depth $>200 \mathrm{~m}$. Eering Strait inflow $15 \mathrm{v}$. Max flux vector $=23 \mathrm{~m} \times 2 / \mathrm{s}$

Figure 5. Circulation pattern and sea-surface heights for model run with real bathymetry and Bering Strait inflow of $1 \mathrm{~Sv}$, no wind forcing, and reduced model friction (left) and with same parameters as on left but with idealized bathymetry such that all depths greater than $200 \mathrm{~m}$ are replaced with $200 \mathrm{~m}$ (right). 

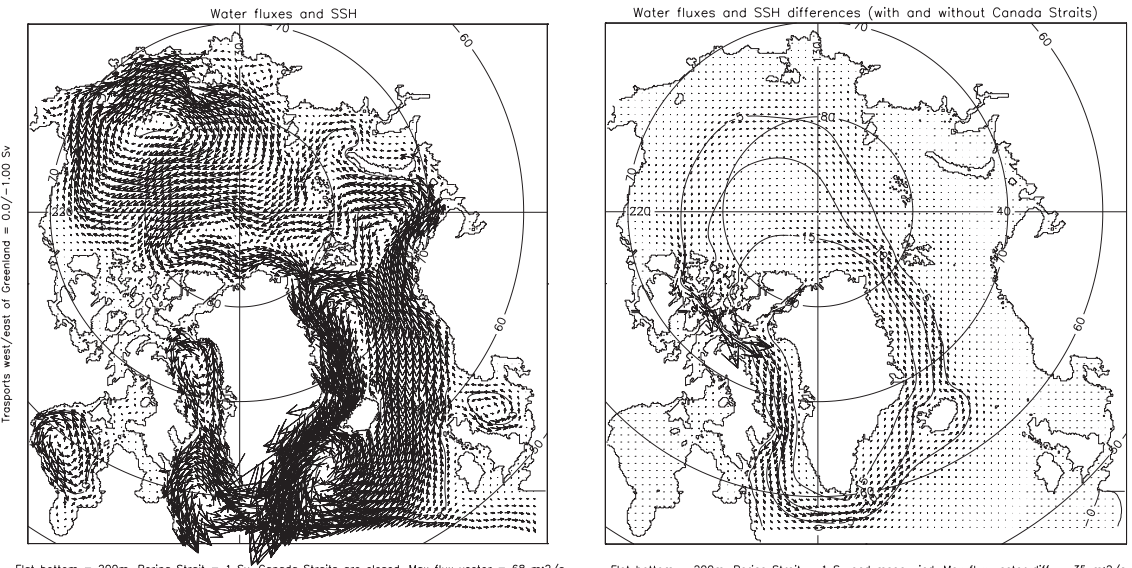

Figure 6. Similar to Figure 4 right, for inflow and mean winds, but the Canada Straits are completely closed (left). The difference between sea surface heights ( $\mathrm{cm}$ ) and circulation (vectors) between experiments with open and closed Canada Straits (right) graphically illustrates the Island Rule dynamics for this model. Neglect of the Straits results in the decrease of the Atlantic water flux to the Arctic Ocean.

case of flat bottom everywhere, beta effect tends to dominate other terms of model equations and this results in the tendency of the flow from Bering Strait to organize a "western boundary current."

The results of wind forcing experiments where the mean, high $\mathrm{AO}$ and low $\mathrm{AO}$ index winds were applied to the ocean with different depths and different friction conditions are all in agreement with the Island Rule theory with friction discussed above and confirm that winds lead to the cyclonic circulation around Greenland and that the correct representation of the Canada strait opening is important for modeling studies.

Among results discussed above, we have selected the flat, 200-m bottom model with 'normal' friction as a point of comparison with the Island Rule calculation (Table 1). For this comparison, both the Inflow and Inflow plus Mean Wind cases show excellent agreement with the theory for the selected friction parameter, which was chosen for tuning to the observations. The dependence on changes in the $\mathrm{AO}$ is also consistent, although the numerical model shows less sensitivity than the theory to the different AO states. This indicates that the tuning of the theory and model can give the correct transports to the west of Greenland for mean conditions, but that they fail to track exactly for anomalous forcing.

Reducing friction leads to an increase flow to the west of Greenland in both the numerical model (Table 2) and the Island Rule dynamics, suggesting that the observed flow there might be used as a means of tuning various Arctic, wind-driven models. Too narrow or too wide Canada Straits in the numerical models can influence the magnitude of the Atlantic water inflow to the Arctic Ocean and the recirculation of the surface waters and freshwater fluxes around Greenland. This final result is illustrated in Figures 4 (right) and Figure 6 (left) where circulation patterns are shown for the case with a flat 200-m bottom, 
mean wind conditions and with and without openings in Canada straits, respectively. The difference between these model runs with and without an opening in the Canada Straits (Fig. 6, right) demonstrates how the Island Rule works for these idealized model simulations.

Our numerical experiments with and without sea ice show that sea ice is mechanically important in separating the ocean surface from winds when sea ice concentration exceeds $90 \%$ and internal ice forces slow down ice drift. This is important to the north and west of Greenland, but since this is not a region of strong winds, the overall effects of sea ice do not fundamentally influence the circum-Greenland circulation.

\section{Discussion}

The flow around Greenland may play a significant role in the freshwater flux out of the Arctic Ocean. The Arctic Ocean is a net exporter of freshwater, not only because of the freshwater inflow from the Pacific, but because of river inputs and export of either melted or frozen (sea ice) water into the Subarctic N. Atlantic. How this freshwater export is partitioned between the two sides of Greenland is of interest, but more importantly, any circum-Greenland transport will pick up freshwater from the Arctic side and return with salty water from the GIN Seas because of lateral mixing. This aspect of the wind-driven flow around Greenland can influence the net export of freshwater from the Arctic, even though there is no thermohaline dynamics involved with this process, except isopycnal mixing. The EGC which transports water southward because of wind-driving, is the western boundary current of the GIN seas, (Fig. 4, right) and provides a substantial dissipation of vorticity as well as freshwater export. It is unlikely that one would observe any northward boundary flow due to circum-Greenland transport we are trying to address. Rather, one might expect a mean deficit in the southward boundary current transport from what is expected on the basis of simple Sverdrup dynamics. This is what is found (Fig. 6, right) in the numerical model calculation. The unbalanced northward flow entering the Arctic would bring Atlantic Water through the Barents Sea and return it west of Greenland. Water mass analysis has lead some investigators (Rudels et al., 2004) to conclude that Atlantic origin, Barents Sea Water is found not only in the Canada Basin, but in Nares Strait; this could be part of the net cyclonic, wind-driven flow around Greenland which we have been studying.

There is some disagreement in the literature about the importance of wind forcing in the Arctic, and in particular the GIN Seas (Carmack, 1990). The paradigm of an "Arctic Mediterranean" driven by buoyancy forcing is evident in the conclusions of a study by Wadhams et al. (1979), which discounted wind-driving as the main driver of the GIN sea circulation and the southward flow of the EGC. Yet flat-bottomed Sverdrup calculations have been published by Aagaard (1970) and Jónsson (1991), based on wind data of lesser duration than our climatology. These latter authors both found the largest cyclonic transport (ca. $30 \mathrm{~Sv}$ ) to the north of Iceland, whereas we find two maxima (Fig. 4b): one to the north of Iceland with a southward EGC transport of $12 \mathrm{~Sv}$ (line A), and another in the Irminger Basin, with southward transport of $21 \mathrm{~Sv}$ (Line B). This latter feature is missing 
from the above, prior studies, which did not go south of $60 \mathrm{~N}$, where our wind stress climatology shows enhanced positive curl in this region (Fig. 2). Lavender et al. (2000) found a strong cyclonic re-circulation within the Irminger Basin and others (Pickart et al., 2005; Lherminier et al., 2007 and Bacon, 1997) have found a southward flow in EGC in the range of 16-22 Sv above the level of the overflow waters, with substantial cyclonic re-circulation within the Irminger Basin. It is possible therefore that this re-circulation feature is a consequence of the wind-driven circulation.

The sensitivity of the circum-Greenland flow to wind variability is addressed in a quasi-steady manner. We have not explicitly addressed the time-dependent response. The barotropic model calculations show that Bering Strait forcing and wind forcing flows approach steady-state after approximately three months of simulation. After two months, the model does not show significant changes in the total model energy and in its potential and kinetic energy components. Sea level and water circulation patterns are relatively stable after less than two months of forcing but this depends upon model friction parameters and with reduced friction it takes longer to reach steady-state conditions. Since we envision that the Island Rule model results apply more to reduced gravity dynamics rather than a barotropic one for time dependence, our quasi-steady assumption is not strictly appropriate for the highly variable decadal forcing of the AO. Brauch and Gerdes (2005) have studied a fully baroclinic, time-dependent response due to an abrupt change from $\mathrm{NAO}+$ to NAO- conditions within a numerical model which included sea ice. They found that 4-7 years after the abrupt change in forcing, the vertically-integrated change in the baroclinic flow was not feeling the effects of the bottom topography through either topographic steering or baroclinic effects (JEBAR), both of which played key roles in the initial response to a change in wind and buoyancy forcing (see their Figs. 12, 13). They also note that during the NAO- phase, freshwater export through Davis Strait was reduced. Although they also performed wind-forced-only changes, there was no analysis of their results on whether the total transport out of the Arctic to the west of Greenland was changed from the control. We hope future calculations of this nature might consider this diagnostic of the Arctic response to variable forcing, perhaps within the framework of the Arctic Ocean Model Intercomparison Project (AOMIP, Proshutinsky et al., 2001, 2005, see also AOMIP web site http://fish.cims.nyu.edu/project_aomip/overview.html).

Our calculations with and without sea ice have shown that sea ice influences water fluxes and their ratio between west and east of Greenland but does not change the major conclusions about the Island Rule circulation discussed above. As we noted earlier, the major region for forcing the wind-driven flow around Greenland is the ice-free region in the N. Atlantic to the east of Greenland's southern tip.

The Island Rule calculation is more sensitive to the different states of the AO than the numerical model. But both indicate the same overall dependence: higher cyclonic flow with increasing AO (or NAO) and vice versa. If one accepts that the friction can be estimated by 'tuning' to the mean state and that this tuning would apply to the variable case, then the Island Rule would predict a larger amplitude of the quasi-time-dependent circulation than the numerical model, although both share a similar partition between 
Bering Strait inflows dividing east and west of Greenland in the model vs. weak friction theory, respectively. One can see (Table 1) that the sense of the Island Rule circulation changes from cyclonic to anti-cyclonic for low AO states. Since the record of direct flow observations does not cover either large or low AO states, one cannot say much more on this at the moment, except to note that a fully time-dependent calculation might be explored before resorting to quasi-steady model results.

The friction parameter chosen can be related to more basic quantities assuming a simple quadratic bottom drag with a drag coefficient of $C_{d}$ : namely $R \vec{u}=C_{d} \vec{u}|\vec{u}| / H$, or more simply, $R=C_{d}|\vec{u}| / H$. If we take a drag coefficient value of $2.6 \times 10^{-3}$, a water depth, $H$ of $200 \mathrm{~m}$, and a velocity scale typical of the observations in the straits of $0.1 \mathrm{~m} / \mathrm{s}$, we obtain a scaling for the friction parameter of $1.3 \times 10^{-6} \mathrm{~s}^{-1}$, which about half what our 'tuned' result gives for a strait aspect ratio $L / W$ of 10 and a Coriolis parameter of $10^{-4} \mathrm{~s}^{-1}: R=0.2 f_{I} W / L \approx 2 \times 10^{-6}$ $\mathrm{s}^{-1}$. While flow velocities of $0.1 \mathrm{~m} / \mathrm{s}$ are seen in the Nares Strait, tidal velocities of even larger magnitude are observed there (Münchow et al., 2006.). Furthermore, these passages in the Canadian Archipelago are ice covered in winter, thus making for top and bottom boundary layers for the flow. Both of these effects would argue for a larger physical value for the frictional scale. Thus, there is rough agreement between our choice of friction and some simple scaling.

If the integration path in (2) had been chosen to be the coastline of Greenland, the only terms in the steady, linear balance would have been the line integral of the wind torque around the island and the dissipation (see Pratt and Pedlosky, 1998),

$$
\oint_{\Gamma}[\vec{T} / \rho+\operatorname{Hdiss}(\vec{u})] \cdot \overrightarrow{d l}=0 .
$$

In the case of bottom friction, the latter can be expressed in terms of the circulation integral around the island. As one can see from the wind stress in Figure 2, there is a substantial southward stress on the east coast of Greenland, which leads to an integral of wind stress of $\approx-630 \mathrm{~m}^{3} \mathrm{~s}^{-2}$, where the path $\Gamma$ is taken counter-clockwise (ccw) around Greenland. This 'torque' must be balanced either by bottom friction or lateral friction, in the case of the numerical model. It is perhaps surprising that despite the fact that our pan-Arctic path integral of (2) along the contour $P$ yields a ccw or cyclonic circulation around Greenland, the dissipation and wind integral around the contour $\Gamma$ suggests just the opposite: a wind forcing and circulation integral with a negative or $\mathrm{cw}$ circulation. This can be understood in terms of the strength of the wind-driven flow and the southward EGC which emerges on the east coast of Greenland, dominates the dissipation, and provides the balance to the wind forcing around the Greenland coast.

The results of this study are important for the modeling of the Arctic Ocean and its variability. Too narrow (or too wide) Canada Straits in numerical models of the Arctic Ocean can influence the magnitude of the Atlantic water inflow to the Arctic Ocean and the recirculation of the surface waters and freshwater fluxes around Greenland. The cyclonic, wind-driven flow around Greenland caused by the Island Rule dynamics enhances the N. 
Atlantic inflow east of Greenland as well as the freshwater export from the Arctic. The latter occurs since the pathway for the freshwater to exit the Arctic through the Canadian Archipelago is shorter than were it to continue flowing eastward to the north of Greenland then southward through Fram Strait. Finally, it should be noted that the Island Rule dynamics depend critically on the variation of the Coriolis parameter with latitude. With an $f$-plane approximation, the solutions tend toward the high friction limit of (3), with vanishing flow to the west of Greenland without wind-driving.

Acknowledgements. One of us (TJ) is grateful for support as the Paul Fye chair for this work, which began while he was visiting LOCEAN at Marie and Pierre Curie University in Paris. Additional support from National Science Foundation grant (OCE-0424865) is also acknowledged. The contribution by AP is supported by the National Science Foundation Office of Polar Programs (under Cooperative Agreement Nos. OPP-0002239 and OPP-0327664) with the International Arctic Research Center, University of Alaska-Fairbanks. We are thankful for comments on a draft of this manuscript by anonymous reviewers and for discussions with colleagues, in particular, Mike Steele and Xin Huang.

\section{REFERENCES}

Aagaard, Knut. 1970. Wind-driven transports in the Greenland and Norwegian seas. Deep-Sea Res., 17, 281-291.

Bacon, Sheldon. 1997. Circulation and fluxes in the North Atlantic between Greenland and Ireland. J. Phys. Oceanogr., 27, 1420-1435.

Brauch, Jennifer P. and Rüdiger Gerdes. 2005. Response of the northern North Atlantic and Arctic oceans to a sudden change of the North Atlantic oscillation. J. Geophys. Res., 110, C11018, doi:10. 1029/2004JC002436

Carmack, Eddy C. 1990. Large-scale physical oceanography of the Polar Oceans, in Polar Oceanography, Part A : Physical Science, Walker O. Smith Jr., ed., Academic Press, 171-223.

Cuny, Jérôme, Peter B. Rhines and Ron Kwok. 2005. Davis Strait volume, freshwater and heat fluxes. Deep-Sea Res. I, 52, 519-542.

Godfrey, J. S. 1989. A Sverdrup model of the depth-integrated flow from the world ocean allowing for island circulations. Geophys. Astrophys. Fluid Dyn., 45, 89-112.

Jónsson, Steingrímur. 1991. Seasonal and interannual variability of wind stress curl over the Nordic Seas. J. Geophys. Res., 96, 2649-2659.

Kowalik, Z. 1981. A study of the M2 tide in the ice-covered Arctic Ocean. Modeling, Identification and Control, 2(4), 201-223.

Kowalik, Z. and A. Y. Proshutinsky. 1994. The Arctic Ocean tides, in The Polar Oceans and Their Role in Shaping the Global Environment; The Nansen Centennial Volume, Geophys. Monogr. Ser., 85, O. Johannessen, R. D. Muench and J. E. Overland, eds., AGU, Washington, D. C., 137-158.

Lavender, K. L., R. E. Davis and W. B. Owens. 2000. Mid-depth recirculation observed in the interior Labrador and Irminger seas by direct velocity measurements. Nature, 407, 66-69.

Lherminier, P., H. Mercier, C. Gourcuff, M. Alvarez, S. Bacon and C. Kermabon. 2007. Transports across the 2002 Greenland-Portugal Ovide section and comparisons with 1997. J. Geophys. Res., 112, C07003, doi:10.1029/2006JC003716.

McPhee, M. G. 1980. Analysis and prediction of short-term ice drift, Proc. 5th Int. Offshore Mechanics and Arctic Engineering Symposium, 4, ASME, 385-393.

Münchow, A., H. Melling and K. Folkner. 2006. An observational estimate of volume and freshwater flux leaving the Arctic Ocean through Nares Strait. J. Phys. Oceanogr., 36, 2025-2041. 
Pedlosky, Joseph, Lawrence J. Pratt, Michael Spall and Karl Helfrich. 1997. Circulation around islands and ridges. J. Mar. Res., 55, 1199-1251.

Pickart, Robert S., Daniel J. Torres and Paula S. Fratantoni. 2005. The East Greenland spill jet. J. Phys. Oceanogr., 35, 1037-1053.

Pratt, Larry and Joseph Pedlosky. 1998. Barotropic circulation around islands with friction. J. Phys. Oceanogr., 28, 2148-2162.

Proshutinsky, A. Y. 1993. Arctic Ocean Level Oscillations. Gidrometeoizdat, St. Petersburg, 216 pp. (in Russian).

Proshutinsky, A. Y. and M. Johnson. 1997. Two circulation regimes of the wind-driven Arctic Ocean. J. Geophys. Res., 102, 12,493-12,514.

Proshutinsky, A., M. Steele, J. Zhang, G. Holloway, N. Steiner, S. Hakkinen, D. Holland, R. Gerdes, C. Koeberle, M. Karcher, M. Johnson, W. Maslowski, W. Walczowski, W. Hibler and J. Wang. 2001. Multinational effort studies differences among Arctic Ocean models. Eos Trans. AGU, 82(51), 637-637, 10.1029/01EO00365.

Proshutinsky, A., J. Yang, R. Krishfield, R. Gerdes, M. Karcher, F. Kauker, C. Koeberle, S. Hakkinen, W. Hibler, D. Holland, M. Maqueda, G. Holloway, E. Hunke, W. Maslowski, M. Steele and J. Zhang. 2005. Arctic Ocean study: Synthesis of model results and observations. Eos Trans. AGU, 86(40), 368, 10.1029/2005EO400003.

Rothrock, D. A. 1975. The mechanical behavior of pack ice. Ann. Rev. Earth Planet. Sci., 3, 317-342.

Rudels, B., E. P. Jones, U. Schauer and P. Eriksson. 2004. Atlantic sources of the Arctic Ocean surface and halocline waters. Polar Res., 2, 181-208.

Thompson, D. W. J. and J. M. Wallace. 1998. The Arctic Oscillation signature in the wintertime geopotential height and temperature fields. Geophys. Res. Lett., 25, 1297-1300.

Wadhams, P., A. E. Gill and P. F. Linden. 1979. Transects by submarine of the East Green Polar Front. Deep-Sea Res., 26A, 1311-1327.

Wajsowicz, R. C. 1996. Flow of a western boundary current through multiple straits: An electrical circuit analogy for the Indonesian throughflow and archipelago. J. Geophys. Res., 101, 1229512300.

Woodgate, R. A., K. Aagaard and T. J. Weingartner. 2006. Interannual changes in the Bering Strait fluxes of volume, heat and freshwater between 1991 and 2004. Geophys. Res. Lett., 33, L15609, doi:10.1029/2006GL026931.

Yang, Jiayan. 2005. The Arctic and Subarctic Ocean flux of potential vorticity and the Arctic Ocean Circulation, J. Phys. Oceanogr., 35, 2387-2407.

Received: 24 August, 2006; revised: 28 September, 2007. 